\title{
Risk Factors for Preterm Delivery in Asymptomatic Singleton Pregnant Women with a Sonographic Short Cervix
}

\author{
Satoshi Yoneda, Noriko Yoneda, Shigeru Saito \\ Department of Obstetrics and Gynecology, University of Toyama, Toyama, Japan \\ Email: s812yone@med.u-toyama.ac.jp
}

How to cite this paper: Yoneda, S., Yoneda, N. and Saito, S. (2021) Risk Factors for Preterm Delivery in Asymptomatic Singleton Pregnant Women with a Sonographic Short Cervix. Open Journal of Obstetrics and Gynecology, 11, 1711-1724.

https://doi.org/10.4236/ojog.2021.1112160

Received: November 21, 2021

Accepted: December 17, 2021

Published: December 20, 2021

Copyright $\odot 2021$ by author(s) and Scientific Research Publishing Inc. This work is licensed under the Creative Commons Attribution International License (CC BY 4.0).

http://creativecommons.org/licenses/by/4.0/

\begin{abstract}
Objectives: Although an asymptomatic short cervix is a risk factor for spontaneous preterm birth (SPTB), the risk factors for SPTB among those with short cervix remain unknown. We herein investigated risk factors for preterm delivery (PTD) at $<34$ weeks of gestation in pregnant women with a short cervix. Methods: This was a retrospective study. Seventy-three asymptomatic pregnant women with a sonographic short cervix (excluding visible bulging fetal membranes) were selected, and the relationship between clinical or biochemical risk factors and preterm delivery (PTD) at $<34$ weeks was examined. Results: Thirteen cases $(17.8 \%)$ had PTD at $<34$ weeks. A univariate analysis showed that a history of SPTD, gestational weeks on admission, cervical length, cervical mucus interleukin (CM-IL)-8 and amniotic fluid interleukin (AF-IL)- 8 in PTD at $<34$ weeks significantly differed from those in delivery at $\geq 34$ weeks ( $\mathrm{p}<0.05$, respectively). A multiple logistic regression analysis identified CM-IL-8 $\geq 803.5 \mathrm{ng} / \mathrm{mL}$ [21.3 (3.0 - 260), $p=0.002]$ and cervical length $\leq 15 \mathrm{~mm}$ [17.1 (1.9 - 517), $p=0.008]$ as independent risk factors for PTD at $<34$ weeks. Conclusions: Evaluation for cervical inflammation may be necessary for appropriate treatment strategies in asymptomatic pregnant women with a short cervix. Cervical inflammation warrants further study.
\end{abstract}

\section{Keywords}

Amniotic Fluid, Cervical Mucus, Interleukin-8, Preterm Delivery, Sonographic Short Cervix

\section{Introduction}

A sonographic short cervix $\leq 25 \mathrm{~mm}$ in the second trimester of pregnancy is a pre-sign of spontaneous preterm birth (SPTB) [1]. Regarding the clinical cha- 
racteristics of SPTB and its problems; 1) since it is just a sonographic sign, a short cervix is only detected in asymptomatic pregnant women using ultrasonography; 2) the positive predictive value of SPTB before 35 weeks was previously reported to be $17.8 \%$ [1], however, the majority of pregnant women delivered after 36 weeks; 3 ) it may be a pre-sign of cervical ripening with bag formation of visible bulging fetal membranes (cervical insufficiency) without clinical symptoms [2] [3], but does not necessarily develop visible bag formation, it might be a pre-sign of preterm labor (PTL) [4] or preterm premature rupture of membranes (pPROM) [5]; and 4) the etiology of a sonographic short cervix may be multifactorial [6], such as vaginal [7] [8], cervical [6] [9] [10], and intra-amniotic [6] [11] [12] [13] [14] [15] inflammation/infection, a history of cervical surgery [6] [16], low cervical collagen concentrations [17], and uterine anomalies [6] [18]. Therefore, the individualized management of asymptomatic pregnant women with a short cervix is needed. However, further studies are needed to clarify which risk factors for SPTB are important.

Intra-amniotic inflammation/infection has been strongly implicated in SPTB [19] [20] [21], and is more severe in the earlier gestational weeks of SPTB [22] [23] [24]. The cause of intra-amniotic inflammation/infection is mainly considered to be an ascending bacterial infection from the vagina through the cervix into the uterine cavity [4] [19] [25]. Therefore, a short cervix may be one of the conditions caused by vaginal, cervical, and/or intra-amniotic inflammation/infection. However, in clinical settings, it currently remains unclear which inflammation/infection is the most important risk factor for SPTB in asymptomatic pregnant women with a short cervix.

In our hospital, when a pregnant woman at risk of SPTB is hospitalized, clinical or chemical risk markers of SPTB, such as the preterm labor index (PLI) [26], maternal body temperature, white blood cell count (WBC), C-reactive protein (CRP), cervical length, Nugent score of vaginal secretions [27], fetal fibronectin (fFN) in vaginal secretions, cervical mucus interleukin (CM-IL)-8, amniotic fluid interleukin (AF-IL)-8 (amniocentesis was administered to asymptomatic pregnant women with a short cervix until March 2008), AF glucose, and AF granulocytes are measured. We previously identified PLI, AF-IL-8, AF glucose, and fFN in vaginal secretions as independent risk factors for PTD at $<34$ weeks in preterm labor (PTL) patients [28].

In the present study, we retrospectively investigated which risk factors correlate with PTD at $<34$ weeks of gestation in asymptomatic pregnant women with a short cervix.

\section{Materials \& Methods}

\subsection{Study Population}

In total, 378 pregnant women before 28 weeks of gestation at risk of SPTB were hospitalized at Toyama University Hospital between April 2000 and March 2008. We excluded patients with multiple pregnancies, fetal growth restriction (less 
than -1.5 S.D.), congenital fetal anomalies, an abnormal fetal karyotype, preeclampsia, gestational diabetes mellitus, a history of cervical surgery, uterine anomalies, and steroid users. We also excluded patients with PTL and PPROM.

Cases in which bag formation of visible bulging membranes was detected in a digital speculum (Cuzco) examination were also excluded. In the present study, cervical insufficiency was defined as visible bulging fetal membranes from the cervix in asymptomatic pregnant women with or without a previous history of SPTB [2]. And "asymptomatic" was defined as a pregnant woman who visited hospital for routine pregnancy check-up. Therefore, the study population was considered to be normal pregnant women without an evaluation by a sonographic examination.

\subsection{Management of Asymptomatic Pregnant Women with a Short Cervix}

Cervical length was routinely measured every 2 weeks between 20 and 28 weeks of gestation with or without clinical symptoms, such as genital bleeding. The length between the internal and external os was assessed by transvaginal ultrasonography.

When asymptomatic pregnant women with a sonographic short cervix were identified in the outpatient clinic, hospitalization for physical rest was recommended. Generally, hospitalization is an exaggerated management (overtreatment), however, our treatment policy was to perform cervical cerclage immediately, when the cervix is suddenly shorter. After hospitalization, we evaluated cervical length every day for first week, and one or two times per week after the first week. Cardiotocogram (CTG) monitoring was also performed one or two times per day. Management strategies, such as therapeutic cerclage (McDonald's cerclage), and maintenance tocolysis [29] [30] were carried out in each case at the discretion of the attending obstetricians. Vaginal progesterone was not administered because it was not covered by the national health insurance system of Japan. Patients were hospitalized from admission to 28 - 30 weeks of gestation. Cases without clinical symptoms, such as regular uterine contractions, were discharged from the hospital and managed in the outpatient clinic.

Transabdominal amniocentesis for research purpose was performed within 2 days of admission after informed written consent had been obtained. The Ethics Committee (No.187) of Toyama University Hospital approved amniocentesis for patients at risk of SPTB to evaluate the AF-IL-8 and infection. Intra-amniotic microbes were evaluated by culture system. Approximately $5-10 \mathrm{~mL}$ of amniotic fluid (AF) was obtained. Amniocentesis was only performed on asymptomatic pregnant women with a sonographic short cervix until March 2008 because of the rarity of asymptomatic cases with severe intra-amniotic inflammation and/or infection.

\subsection{Study Procedures and Statistical Analysis}

Demographic and clinical data [maternal age, nullipara, a history of SPTB, pre- 
pregnancy body mass index (BMI), smoking during pregnancy, gestational weeks on admission, maternal body temperature, WBC, CRP, cervical length, Nugent score, fFN in vaginal secretions, CM-IL-8, AF-IL-8, AF-glucose, AF-WBC, AFmicrobes, tocolysis, cerclage, gestational weeks at birth, neonatal birth weight, still birth, Apgar scores, and admission to the NICU] were collected and compared between delivery at $<34$ weeks and $\geq 34$ weeks [31].

Risk factors associated with preterm delivery at $<34$ weeks of gestation (PTD at $<34$ weeks) were assessed using a univariate analysis, which was performed using the $\chi^{2}$-test or Mann-Whitney $U$ test, where appropriate. Cut-off values for risk factors were analyzed using a receiver operating characteristics (ROC) curve, and independent risk factors were investigated using a multiple regression logistic analysis. All analyses were performed using statistical analysis software (JMP, version 11.2.0; SAS Institute Inc., Tokyo, Japan). A $p$-value $<0.05$ was considered to be significant.

We also discussed the pathology and management strategy for asymptomatic pregnant women with a short cervix based on the results of this retrospective study.

\section{Results}

Seventy-three asymptomatic pregnant women with a sonographic short cervix $\leq 25$ $\mathrm{mm}$ were selected in the present study (Figure 1), and 13 cases delivered at $<34$ weeks (17.8\%: 13/73)

Table 1 shows a comparison of clinical characteristics between asymptomatic pregnant women with a sonographic short cervix with PTD at $<34$ weeks and delivery at $\geq 34$ weeks. A history of PTB (57.1\%), CM-IL-8 [803.5 (26.9 - 2785.9) $\mathrm{ng} / \mathrm{mL}$ ], AF-IL-8 [6.4 $(0.3-138) \mathrm{ng} / \mathrm{mL}$ ], and tocolytis $(100 \%)$ in PTD at $<34$ weeks were significantly higher than those $[15.8 \%, 154.8(1.9-2229.5) \mathrm{ng} / \mathrm{mL}$, $2.2(0.1-30.8) \mathrm{ng} / \mathrm{mL}$, and 60\%, respectively] in Delivery at $\geq 34$ weeks. On the other hand, gestational age on admission [21 (19 - 26) weeks] and cervical length on admission [13 $(5-24) \mathrm{mm}$ ] in PTD at $<34$ weeks was significantly lower than those [25 (16 - 28) weeks and $17(5-25) \mathrm{mm}$, respectively] in Delivery at $\geq 34$ weeks.

Gestational weeks on admission $\leq 23$ weeks (AUC $=0.762$ ), AF-IL-8 $\geq 2.4$ $\mathrm{ng} / \mathrm{mL}$ (AUC $=0.706$ ), CM-IL-8 $\geq 803.5 \mathrm{ng} / \mathrm{mL}$ (AUC $=0.729$ ), and cervical length $\leq 15 \mathrm{~mm}$ (AUC $=0.726$ ) were cut-off values that correlated with PTD at $<34$ weeks using the ROC curve (Figure 2).

Table 2 shows independent risk factors for PTD at $<34$ weeks identified by a multiple logistic regression analysis. CM-IL-8 $\geq 803.5 \mathrm{ng} / \mathrm{mL}[21.3$ (3.0 - 260), $\mathrm{p}=0.002]$ and $\mathrm{CL}$ on admission $\leq 15 \mathrm{~mm}[17.1(1.9-517), \mathrm{p}=0.008]$ were independent risk factors.

Diagnostic values for predicting PTD at $<34$ weeks were sensitivity of $53.8 \%$ and specificity of $93.3 \%$ for CM-IL- 8 ( $\geq 803.5 \mathrm{ng} / \mathrm{mL}$ ), and $76.9 \%$ and $63.3 \%$, respectively, for CL on admission ( $\leq 15 \mathrm{~mm}$ ) (Table 3 ). Positive predictive values 
Three-hundred-seventy-eight pregnant women before 28 weeks of gestation with a risk of spontaneous preterm birth had hospitalized at our hospital between 2000 and 2008 .

Multiple pregnancies, fetal growth restriction (less than -1.5 S.D.), congenital fetal anomalies, abnormal fetal karyotype, preeclampsia, gestational diabetes mellitus, history of cervical operation, uterine anomalies and steroid users were excluded $(n=53)$.

One-hundred-twenty-three asymptomatic pregnant women with sonographic short cervix $\leq 25 \mathrm{~mm}$ were managed.

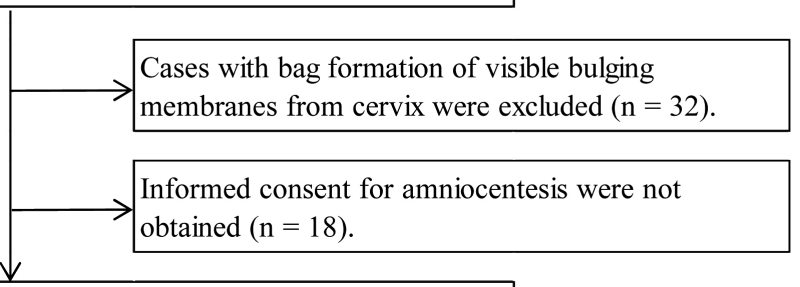

Seventy-three asymptomatic pregnant women with sonographic short cervix $\leq 25 \mathrm{~mm}$ were selected in this study.

Figure 1. Study profile.

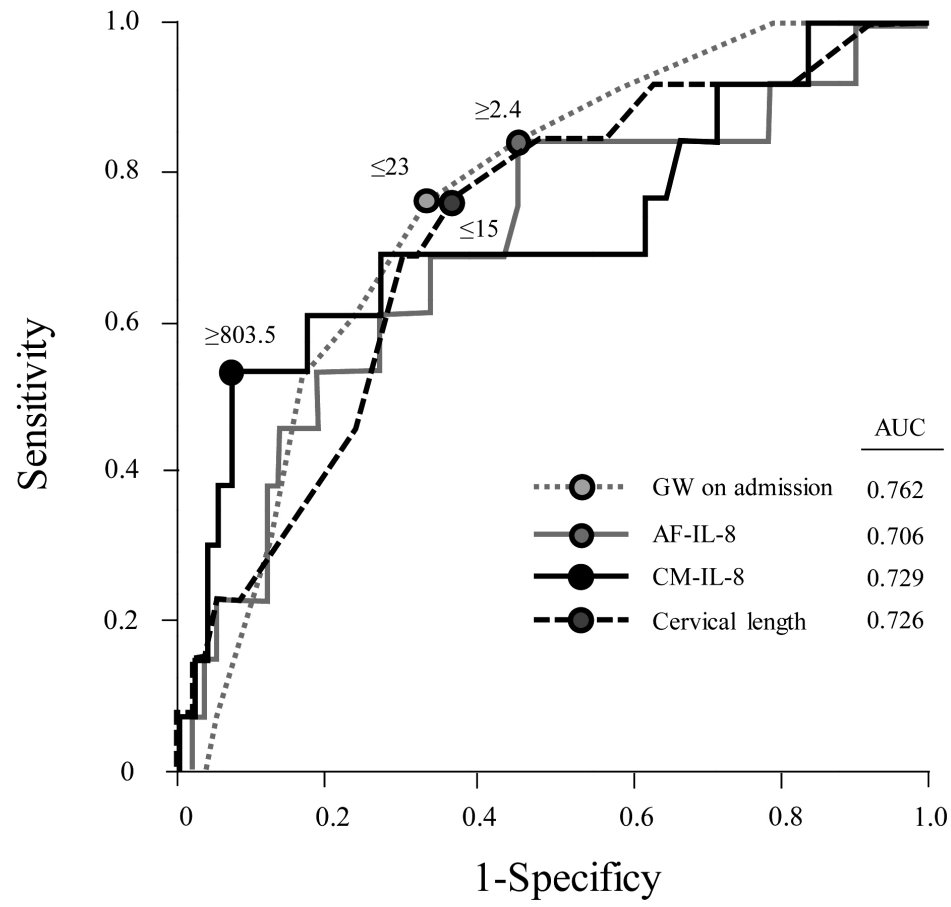

Figure 2. Receiver operating characteristic curves of each rick factor for preterm delivery at $<34$ weeks of gestation in asymptomatic pregnant women with a short cervix $\leq 25 \mathrm{~mm}$. The cut-off values were $\leq 23$ weeks of gestational weeks on admission [area under the curve (AUC) 0.762 ] $\geq 2.4 \mathrm{ng} / \mathrm{mL}$ of AF-IL-8 (AUC 0.706), $\geq 803.5 \mathrm{ng} / \mathrm{mL}$ of CM-IL-8 (AUC 0.729), and $\leq 15 \mathrm{~mm}$ of cervical length (AUC 0.726), respectively. 
Table 1. Clinical characteristics of asymptomatic pregnant women with sonographic short cervix between PTD at $<34$ weeks and Delivery $\geq 34$ weeks of gestation.

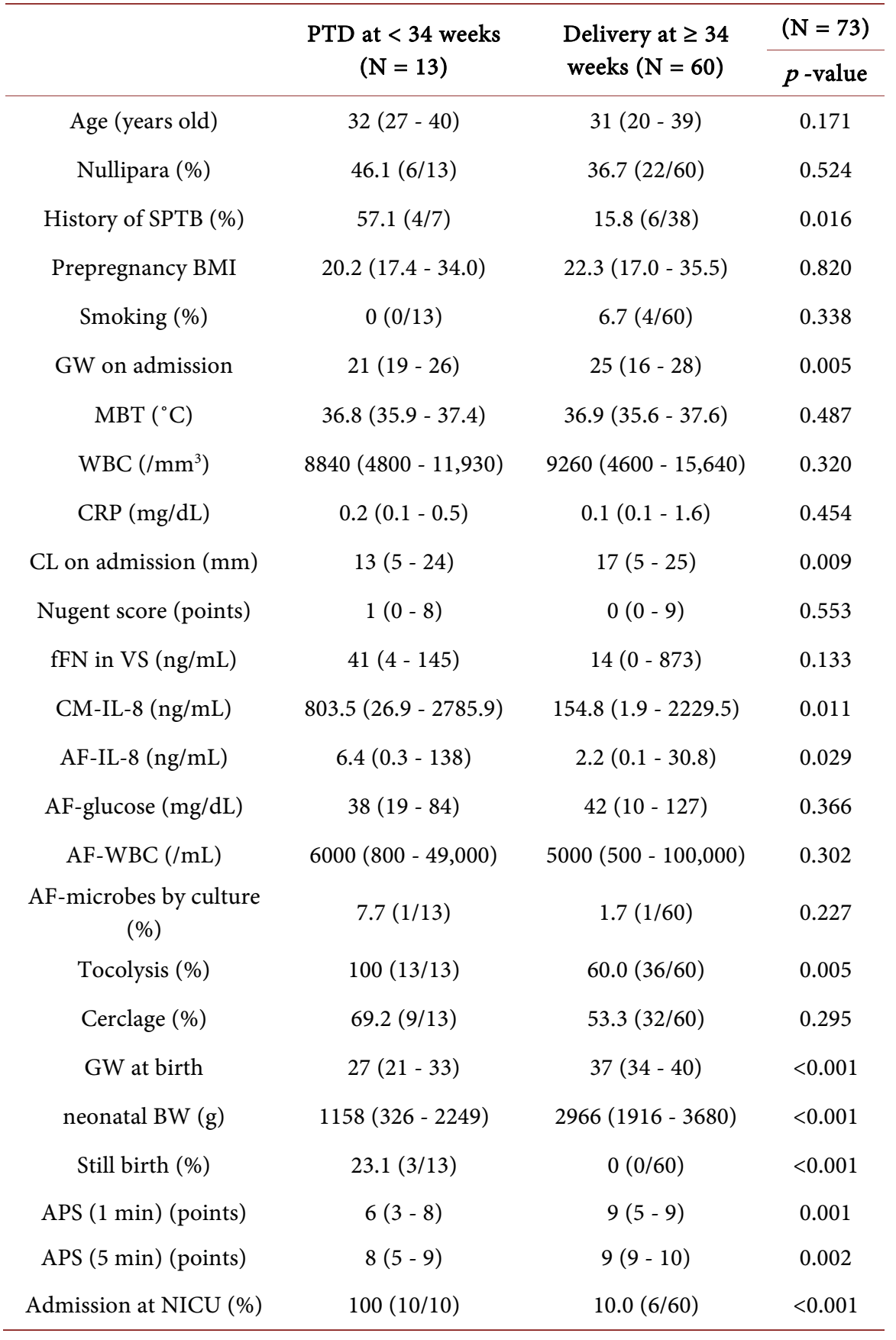

PTD; preterm delivery, SPTB; spontaneous preterm birth, BMI; body mass index, GW; gestational weeks, MBT; maternal body temprature, WBC; white blood cell count, CRP; C-reactive protein, $\mathrm{CL}$; cervical length, fFN; fetal fibronectin, VS; vaginal secretions, CM; cervical mucus, IL; interleukin, AF; amniotic fluid, BW; body weight, APS; Apgar score, NICU; neonatal intensive care unit.

were $63.6 \%$ for CM-IL-8 and $31.2 \%$ for CL on admission. On the other hand, negative predictive values were $90.3 \%$ for CM-IL- 8 and $92.7 \%$ for CL on admission. 
Table 2. Independent risk factors for PTD at $<34$ weeks of gestation by multiple logistic regression analysis.

\begin{tabular}{cccc}
\hline Factor & Odd Ratio & $95 \% \mathrm{CI}$ & $(\mathrm{N}=\mathbf{7 3})$ \\
\cline { 4 - 4 } & & & $p$-value \\
\hline History of PTB & 11.1 & $0.76-400$ & 0.079 \\
GW on admission $(\leq 23$ weeks $)$ & 5.8 & $0.92-57.8$ & 0.062 \\
AF-IL-8 $(\geq 2.4 \mathrm{ng} / \mathrm{mL})$ & 5.7 & $0.90-61.1$ & 0.065 \\
CM-IL-8 $(\geq 803.5 \mathrm{ng} / \mathrm{mL})$ & 21.3 & $3.0-260$ & 0.002 \\
CL on admission $(\leq 15 \mathrm{~mm})$ & 17.1 & $1.9-517$ & 0.008 \\
\hline
\end{tabular}

PTD; preterm delivery, PTB; preterm birth, CI; confidence interval, GW; geatational weeks, AF; amniotic fluid, IL; interleukin, CM; cervical mucus, CL; cervical length.

Table 3. Diagnostic values for predicting PTD at $<34$ weeks of gestation $(n=73)$.

\begin{tabular}{ccccc}
\hline & Sensitivity (\%) & Specificity (\%) & PPV (\%) & NPV (\%) \\
\hline $\begin{array}{c}\text { CM-IL-8 }(\geq 803.5 \mathrm{ng} / \mathrm{mL}) \\
\begin{array}{c}\text { CL on admission } \\
(\leq 15 \mathrm{~mm})\end{array}\end{array}$ & $53.8(7 / 13)$ & $93.3(56 / 60)$ & $63.6(7 / 11)$ & $90.3(56 / 62)$ \\
$\begin{array}{c}\text { CM-IL-8 \& CL } \\
\text { (10/13) }\end{array}$ & $63.3(38 / 60)$ & $31.2(10 / 32)$ & $92.7(38 / 41)$ \\
\hline
\end{tabular}

PTD; preterm delivery, PPV; positive predictive value, NPV; negative predictive value, CM; cervical mucus, IL; interleukin, CL; cervical length.

\section{Discussion}

\subsection{Clinical Significance}

We generally examine cervical length using ultrasonography in the outpatient clinic between 22 to 24 weeks of gestation because a short cervix is a pre-sign of SPTB. The early detection of this pre-sign before the appearance of clinical symptoms, such as cervical insufficiency (visible bag formation), PTL, or PPROM, looks to be beneficial.

Management strategies for asymptomatic pregnant women with a short cervix include the administration of progesterone [32] [33] [34], therapeutic cerclage [35] [36] [37], a vaginal pessary [38] [39] [40]. However, these treatment strategies had not been administered according to each etiology. The strategy based on the pathological condition may improve the prognosis. On the other hand, previous studies pointed out that the pregnant women with a short cervix had delivered at term without treatment in most cases [41] [42] [43]. Therefore, observation without treatment would be better choice in some cases.

In the present study, the following 5 risk factors for PTD at $<34$ weeks were identified in the univariable analysis; a history of SPTB, gestational weeks on admission $\leq 23$ weeks, AF-IL- $8 \geq 2.4 \mathrm{ng} / \mathrm{mL}$, CM-IL- $8 \geq 803.5 \mathrm{ng} / \mathrm{mL}$, and cervical length $\leq 15 \mathrm{~mm}$. Therefore, management strategies according to each risk factor are possible. In particular, CM-IL-8 and cervical length were identified as independent risk factors. 
Although there was a significant difference in amniotic inflammation by univariable analysis, the level of inflammation was extremely low [24]. It is clinically important that the intra-uterine environment is still maintained in asymptomatic pregnant women with short cervix.

\subsection{Cervical Inflammation}

Based on our previous findings, CM-IL-8 $\geq 803.5 \mathrm{ng} / \mathrm{mL}$ indicates severe cervical inflammation (cervicitis $>360 \mathrm{ng} / \mathrm{mL}$ ) [44], which may be strongly associated with SPTB. In the pathology of asymptomatic short cervical cases, cervical inflammation may play a crucial role in shortening mechanisms.

Progesterone exerts anti-inflammatory effects [45] [46], and natural progesterone is often used in the treatment of asymptomatic short cervical cases to prevent SPTB [8] [34] [47]. Therefore, the present results may indicate its efficacy against local severe inflammation in the cervix.

\subsection{Short Cervix $\leq 15 \mathrm{~mm}$}

Decreases in cervical length may increase the risk of SPTB [48]. In the present study, cervical length $\leq 15 \mathrm{~mm}$ was identified as an independent risk factor for PTD at $<34$ weeks with or without a history of SPTB. Previous studies reported a correlation between a short cervix $\leq 15 \mathrm{~mm}$ and SPTB [49] [50], which is consistent with the present results.

The efficacy of therapeutic cerclage has been suggested for patients with a short cervix $\leq 15 \mathrm{~mm}$ [51] [52] [53]. Therapeutic cerclage was recently shown to significantly reduce PTD at $<35$ weeks of gestation in patients with a short cervix $<10 \mathrm{~mm}$ and no history of SPTB, who are at a high risk of SPTB [37]. Considering these reports and our results, the therapeutic cerclage is not necessary for cases with cervical length more than $16 \mathrm{~mm}$.

\subsection{Strengths and Limitations of the Present Study}

The present study had the following strengths: 1) Although the etiology of or risk factors for SPTB in asymptomatic short cervical pregnant women have been extensively examined, there is no report that which factors associated with SPTB is more important by a multiple regression analysis. 2) This is the first study to clarify whether cervical or intra-amniotic inflammation is more important using inflammatory markers, such as IL-8. 3) The present results advocate the clinical concept that manages patients with a short cervix according to each individual cause. Therefore, the present results may lead to be a new logical and novel management strategy. For example, hospitalization, progesterone, and cerclage may not be necessary in asymptomatic short cervical cases at a low risk of SPTD. We previously reported that elevated CM-IL-8 in cerclage cases was an indicator of SPTD [35].

The present study had the following limitations: 1) The number of patients examined was small (73 cases), the $95 \%$ confidence interval (CI) was larger, and 
clinical data were gathered from a single hospital; however, further studies with a large number of patients will increase its significance. 2) Although severe cervicitis is significant risk factor for PTD at $<34$ weeks, the cause of cervicitis was not identified in the present study. Vaginal microbes, such as bacteria and/or Ureaplasma/ Mycoplasma [54], which have recently been reported to correlate with SPTB [55] [56], may contribute to severe cervicitis; however, the Nugent score was not related in this study. 3) Although the rate of therapeutic cerclage for a short cervix was high, a significant difference was not observed between the two groups (PTD at $<34$ weeks vs. Delivery at $\geq 34$ weeks).

\subsection{Proposals for Future Research}

In the management of asymptomatic pregnant woman with a short cervix, we propose the selection of suitable strategies based on each etiology. Therefore, the mechanisms contributing to cervical shortening without clinical symptoms need to be elucidated. Furthermore, large clinical studies, such as randomized controlled trials, are needed to clarify the ascending mechanisms of vaginal, cervical, and intra-amniotic inflammation and/or infection.

\section{Conclusion}

Risk factors for SPTD at $<34$ weeks in asymptomatic pregnant women with a sonographic short cervix include a history of SPTD, a shorter cervix $(\leq 15 \mathrm{~mm})$, and cervical and/or amniotic inflammation. However, the value of AF-IL-8 was very low in most cases. Appropriate treatment strategies need to be planned according to each risk factor. Especially, severe cervical inflammation and shorter cervix $(\leq 15 \mathrm{~mm})$ were independent risk factors. It is clinically important that the inflammation in cervix rather than in amnion was more significant. Further studies are also needed to assess cervical inflammation.

\section{Acknowledgements}

We thank the mothers who participated in this study. This research was supported by a Grant-in-Aid for Scientific Research from the Japanese Ministry of Education, Culture, Sports, Science and Technology (JSPS KAKENHI No. 21K09535).

\section{Date Availability Statement}

The data used to support the present results are available from the corresponding authors on reasonable request.

\section{Authors' Contributions}

Satoshi Yoneda conceptualized the study design. Satoshi Yoneda and Noriko Yoneda gathered and statistically analyzed clinical data. Satoshi Yoneda wrote the first draft of the manuscript. Shigeru Saito provided further technical and editorial inputs. The manuscript was reviewed and approved by all authors be- 
fore its submission.

\section{Conflicts of Interest}

There is no financial or other relationship that may lead to a conflict of interest.

\section{References}

[1] Iams, J.D., Goldenberg, R.L., Meis, P.J., Mercer, B.M., Moawad, A., et al. (1996) The Length of the Cervix and the Risk of Spontaneous Premature Delivery. National Institute of Child Health and Human Development Maternal Fetal Medicine Unit Network. New England Journal of Medicine, 334, 567-572.

https://doi.org/10.1056/NEJM199602293340904

[2] American College of Obstetricians and Gynecologists (2014) Practice Bulletin No.142: Cerclage for the Management of Cervical Insufficiency. Obstetrics \& Gynecology, 123, 372-379. https://doi.org/10.1097/01.AOG.0000443276.68274.cc

[3] Lidegaard, O. (1994) Cervical Incompetence and Cerclage in Denmark 1980-1990. A Register Based Epidemiological Survey. Acta Obstetricia et Gynecologica Scandinavica, 73, 35-38. https://doi.org/10.3109/00016349409013390

[4] Romero, R., Dey, S.K. and Fisher, S.J. (2014) Preterm Labor: One Syndrome, Many Causes. Science, 345, 760-765. https://doi.org/10.1126/science.1251816

[5] Tchirikov, M., Schlabritz-Loutsevitch, N., Maher, J., Buchmann, J., Naberezhnev, Y., Winarno, A.S., et al. (2018) Mid-Trimester Preterm Premature Rupture of Membranes (PPROM): Etiology, Diagnosis, Classification, International Recommendations of Treatment Options and Outcome. Journal of Perinatal Medicine, 46, 465-488. https://doi.org/10.1515/jpm-2017-0027

[6] Guimaraes Filho, H.A., Araujo Junior, E., Pires, C.R., Nardozza, L.M. and Moron, A.F. (2013) Short Cervix Syndrome: Current Knowledge from Etiology to the Control. Archives of Gynecology and Obstetrics, 287, 621-628. https://doi.org/10.1007/s00404-013-2740-0

[7] Sendag, F., Kazandi, M., Akercan, F., Kazandi, A.C., Karadadas, N. and Sagol, S. (2010) Vaginal Fluid pH, Cervicovaginitis and Cervical Length in Pregnancy. Clinical and Experimental Obstetrics \& Gynecology, 37, 127-130.

[8] Kindinger, L.M., Bennett, P.R., Lee, Y.S., Marchesi, J.R., Smith, A., Cacciatore, S., et al. (2017) The Interaction between Vaginal Microbiota, Cervical Length, and Vaginal Progesterone Treatment for Preterm Birth Risk. Microbiome, 5, Article No. 6. https://doi.org/10.1186/s40168-016-0223-9

[9] Choi, S.R., Hong, S.S., Kim, J. and Lee, K.Y. (2018) Neutrophil Elastase in Cervical Fluid in Women with Short Cervical Length. Taiwanese Journal of Obstetrics and Gynecology, 57, 407-410. https://doi.org/10.1016/j.tjog.2018.04.014

[10] Yoo, H.N., Park, K.H., Jung, E.Y., Kim, Y.M., Kook, S.Y. and Jeon, S.J. (2017) Non-Invasive Prediction of Preterm Birth in Women with Cervical Insufficiency or an Asymptomatic Short Cervix $(\leq 25 \mathrm{~mm})$ by Measurement of Biomarkers in the Cervicovaginal Fluid. PLoS ONE, 12, e0180878.

https://doi.org/10.1371/journal.pone.0180878

[11] Hassan, S., Romero, R., Hendler, I., Gomez, R., Khalek, N., Espinoza, J., et al. (2006) A Sonographic Short Cervix as the Only Clinical Manifestation of Intra-Amniotic Infection. Journal of Perinatal Medicine, 34, 13-19. https://doi.org/10.1515/JPM.2006.002

[12] Tarca, A.L., Fitzgerald, W., Chaemsaithong, P., Xu, Z., Hassan, S.S., Grivel, J.-C., et 
al. (2017) The Cytokine Network in Women with an Asymptomatic Short Cervix and the Risk of Preterm Delivery. American Journal of Reproductive Immunology, 78, e12686. https://doi.org/10.1111/aji.12686

[13] Kiefer, D., Keeler, S., Rust, O., Chow, S.S.W., Craig, M.E., Peltier, M.R., et al. (2012) Amniotic Fluid Inflammatory Score Is Associated with Pregnancy Outcome in Patients with Mid Trimester Short Cervix. American Journal of Obstetrics \& Gynecology, 206, 68.e1-68.e6. https://doi.org/10.1016/j.ajog.2011.08.002

[14] Kiefer, D.G., Keeler, S.M., Rust, O.A., Wayock, C.P., Vintzileos, A.M. and Hanna, N. (2009) Is Midtrimester Short Cervix a Sign of Intraamniotic Inflammation? American Journal of Obstetrics \& Gynecology, 200, 374.e1-374.e5. https://doi.org/10.1016/j.ajog.2009.01.047

[15] Vaisbuch, E., Hassan, S.S., Mazaki-Tovi, S., Nhan-Chang, C.-L., Pedro Kusanovic, J., Chaiworapongsa, T., et al. (2010) Patients with an Asymptomatic Short cervIx $(\leq 15 \mathrm{~mm})$ Have a High Rate of Subclinical Intra-Amniotic Inflammation: Implications for Patient Counseling. American Journal of Obstetrics \& Gynecology, 202, 433.e1-433.e8. https://doi.org/10.1016/j.ajog.2010.02.007

[16] Boelig, R.C., Villani, M., Jiang, E., Orzechowski, K.M. and Berghella, V. (2018) Prior Uterine Evacuation and the Risk of Short Cervical Length: A Retrospective Cohort Study. Journal of Ultrasound in Medicine, 37, 1763-1769.

https://doi.org/10.1002/jum.14529

[17] Sundtoft, I., Langhoff-Roos, J., Sandager, P., Sommer, S. and Uldbjerg, N. (2017) Cervical Collagen Is Reduced in Non-Pregnant Women with a History of Cervical Insufficiency and a Short Cervix. Acta Obstetricia et Gynecologica Scandinavica, 96, 984-990. https://doi.org/10.1111/aogs.13143

[18] Crane, J.M. and Hutchens, D. (2008) Transvaginal Sonographic Measurement of Cervical Length to Predict Preterm Birth in Asymptomatic Women at Increased Risk: A Systematic Review. Ultrasound in Obstetrics \& Gynecology, 31, 579-587. https://doi.org/10.1016/S0140-6736(08)60074-4

[19] Goldenberg, R.L., Culhane, J.F., Iams, J.D. and Romero, R. (2008) Epidemiology and Causes of Preterm Birth, Lancet, 371, 75-84. https://doi.org/10.1016/S0140-6736(08)60074-4

[20] Purisch, S.E. and Gyamfi-Bannerman, C. (2017) Epidemiology of Preterm Birth. Seminars in Perinatology, 41, 387-391.

https://doi.org/10.1053/j.semperi.2017.07.009

[21] Frey, H.A. and Klebanoff, M.A. (2016) The Epidemiology, Etiology, and Costs of Preterm Birth. Seminars in Fetal \& Neonatal Medicine, 21, 68-73. https://doi.org/10.1016/j.siny.2015.12.011

[22] Romero, R., Miranda, J., Chaiworapongsa, T., Korzeniewski, S.J., Chaemsaithong, P., Gotsch, F., et al. (2014) Prevalence and Clinical Significance of Sterile IntraAmniotic Inflammation in Patients with Preterm Labor and Intact Membranes. American Journal of Reproductive Immunology, 72, 458-474. https://doi.org/10.1111/aji.12296

[23] Lahra, M.M. and Jeffery, H.E. (2004) A Fetal Response to Chorioamnionitis Is Associated with Early Survival after Preterm Birth. American Journal of Obstetrics \& Gynecology, 190, 147-151. https://doi.org/10.1016/j.ajog.2003.07.012

[24] Yoneda, S., Shiozaki, A., Ito, M., Yoneda, N., Inada, K., Yonezawa, R., et al. (2015) Accurate Prediction of the Stage of Histological Chorioamnionitis before Delivery by Amniotic Fluid IL-8 Level. American Journal of Reproductive Immunology, 73, 568-576. https://doi.org/10.1111/aji.12360 
[25] Liu, L., Oza, S., Hogan, D., Perin, J., Rudan, I., Lawn, J.E., et al. (2015) Global, Regional, and National Causes of Child Mortality in 2000-13, with Projections to Inform Post-2015 Priorities: An Updated Systematic Analysis. Lancet, 385, 430-440. https://doi.org/10.1016/S0140-6736(14)61698-6

[26] Sakai, M., Sasaki, Y., Yamagishi, N., Tanebe, K., Yoneda, S. and Saito, S. (2003) The Preterm Labor Index and Fetal Fibronectin for Prediction of Preterm Delivery with Intact Membranes. Obstetrics \& Gynecology, 101, 123-128. https://doi.org/10.1097/00006250-200301000-00024

[27] Nugent, R.P., Krohn, M.A. and Hillier, S.L. (1991) Reliability of Diagnosing Bacterial Vaginosis Is Improved by a Standardized Method of Gram Stain Interpretation. Journal of Clinical Microbiology, 29, 297-301. https://doi.org/10.1128/jcm.29.2.297-301.1991

[28] Yoneda, S., Sakai, M., Sasaki, Y., Shiozaki, A., Hidaka, T. and Saito, S. (2007) Interleukin-8 and Glucose in Amniotic Fluid, Fetal Fibronectin in Vaginal Secretions and Preterm Labor Index Based on Clinical Variables Are Optimal Predictive Markers for Preterm Delivery in Patients with Intact Membranes. Journal of Obstetrics and Gynaecology Research, 33, 38-44. https://doi.org/10.1111/j.1447-0756.2007.00474.x

[29] Yoneda, S. (2020) Method to Evaluate Intravenous Maintenance Tocolysis for Preterm Labor. Journal of Obstetrics and Gynaecology Research, 46, 2518-2525. https://doi.org/10.1111/jog.14484

[30] Yoneda, S., Yoneda, N., Fukuta, K., Shima, T., Nakashima, A., Shiozaki, A., et al. (2018) In Which Preterm Labor-Patients Is Intravenous Maintenance Tocolysis Effective? Journal of Obstetrics and Gynaecology Research, 44, 397-407. https://doi.org/10.1111/jog.13547

[31] Kramer, M.S., Demissie, K., Yang, H., Platt, R.W., Sauvé, R. and Liston, R. (2000) The Contribution of Mild and Moderate Preterm Birth to Infant Mortality. Fetal and Infant Health Study Group of the Canadian Perinatal Surveillance System. JAMA, 284, 843-849. https://doi.org/10.1001/jama.284.7.843

[32] Fonseca, E.B., Celik, E., Parra, M., Singh, M. and Nicolaides, K.H., for the Fetal Medicine Foundation Second Trimester Screening Group (2007) Progesterone and the Risk of Preterm Birth among Women with a Short Cervix. New England Journal of Medicine, 357, 462-469. https://doi.org/10.1056/NEJMoa067815

[33] Conde-Agudelo, A., Romero, R., Da Fonseca, E., O’Brien, J.M., Cetingoz, E., Creasy, G.W., et al. (2018) Vaginal Progesterone Is as Effective as Cervical Cerclage to Prevent Preterm Birth in Women with a Singleton Gestation, Previous SPTB, and a Short Cervix: Updated Indirect Comparison Meta-Analysis. American Journal of Obstetrics \& Gynecology, 219, 10-25. https://doi.org/10.1016/j.ajog.2018.03.028

[34] Romero, R., Conde-Agudelo, A., Da Fonseca, E., O’Brien, J.M., Cetingoz, E., Creasy, G.W., et al. (2018) Vaginal Progesterone for Preventing Preterm Birth and Adverse Perinatal Outcomes in Singleton Gestations with a Short Cervix: A Meta-Analysis of Individual Patient Data. American Journal of Obstetrics \& Gynecology, 218, 161 180. https://doi.org/10.1016/j.ajog.2017.11.576

[35] Alfirevic, Z., Stampalija, T. and Medley, N. (2017) Cervical Stitch (Cerclage) for Preventing Preterm Birth in Singleton Pregnancy. Cochrane Database of Systematic Reviews, No. 6, Article No. CD008991. https://doi.org/10.1002/14651858.CD008991.pub3

[36] Romero, R., Espinoza, J., Erez, O. and Hassan, S. (2006) The Role of Cervical Cerclage in Obstetric Practice: Can the Patient Who Could Benefit from This Procedure Be Identified? American Journal of Obstetrics \& Gynecology, 194, 1-9. https://doi.org/10.1016/j.ajog.2005.12.002 
[37] Berghella, V., Ciardulli, A., Rust, O.A., To, M., Otsuki, K., Althuisius, S., et al. (2017) Cerclage for Sonographic Short Cervix in Singleton Gestations without Prior Spontaneous Preterm Birth: Systematic Review and Meta-Analysis of Randomized Controlled Trials Using Individual Patient-Level Data. Ultrasound in Obstetrics \& Gynecology, 50, 569-577. https://doi.org/10.1002/uog.17457

[38] Nicolaides, K.H., Syngelaki, A., Poon, L.C., Picciarelli, G., Tul, N., Zamprakou, A., et al. (2016) A Randomized Trial of a Cervical Pessary to Prevent Preterm Singleton Birth. New England Journal of Medicine, 374, 1044-1052.

https://doi.org/10.1056/NEJMoa1511014

[39] Saccone, G., Maruotti, G.M., Giudicepietro, A., Martinelli, P., Italian Preterm Birth Prevention (IPP) Working Group (2017) Effect of Cervical Pessary on Spontaneous Preterm Birth in Women with Singleton Pregnancies and Short Cervical Length: A Randomized Clinical Trial. JAMA, 318, 2317-2324.

https://doi.org/10.1001/jama.2017.18956

[40] Dugoff, L., Berghella, V., Sehdev, H., Mackeen, A.D., Goetzl, L. and Ludmir, J. (2018) Prevention of Preterm Birth with Pessary in Singletons (PoPPS): Randomized Controlled Trial. Ultrasound in Obstetrics \& Gynecology, 51, 573-579. https://doi.org/10.1002/uog.18908

[41] Orzechowski, K.M., Boelig, R., Nicholas, S.S., Baxter, J. and Berghella, V. (2015) Is Universal Cervical Length Screening Indicated in Women with Prior Term Birth? American Journal of Obstetrics \& Gynecology, 212, 234.e1-234.e5. https://doi.org/10.1016/j.ajog.2014.08.029

[42] Facco, F.L. and Simhan, H.N. (2013) Short Ultrasonographic Cervical Length in Women with Low-Risk Obstetric History. Obstetrics \& Gynecology, 122, 858-862. https://doi.org/10.1097/AOG.0b013e3182a2dccd

[43] van der Ven, J., van Os, M.A., Kazemier, B.M., Kleinrouweler, C.E., Verhoeven, C.J., de Miranda, E., et al. (2015) The Capacity of Mid-Pregnancy Cervical Length to Predict Preterm Birth in Low-Risk Women: A National Cohort Study. Acta Obstetricia et Gynecologica Scandinavica, 94, 1223-1234.

https://doi.org/10.1111/aogs.12721

[44] Sakai, M., Sasaki, Y., Yoneda, S., et al. (2004) Elevated Interleukin-8 in Cervical Mucus as an Indicator for Treatment to Prevent Premature Birth and Preterm, Pre-Labor Rupture of Membranes: A Prospective Study. American Journal of Reproductive Immunology, 51, 220-225. https://doi.org/10.1111/j.1600-0897.2004.00145.x

[45] Hung, T.H., Chen, S.F., Wu, C.P., Li, M.J., Yeh, Y.L. and Hsieh, T.T. (2017) Micronized Progesterone Pretreatment Affects the Inflammatory Response of Human Gestational Tissues and the Cervix to Lipopolysaccharide Stimulation. Placenta, 57, 1-8. https://doi.org/10.1016/j.placenta.2017.05.013

[46] Yoshino, O., Osuga, Y., Hirota, Y., Koga, K., Hirata, T., Yano, T., et al. (2003) Endometrial Stromal Cells Undergoing Decidualization Down-Regulate Their Properties to Produce Proinflammatory Cytokines in Response to Interleukin-1 Beta via Reduced p38 Mitogen-Activated Protein Kinase Phosphorylation. The Journal of Clinical Endocrinology \& Metabolism, 88, 2236-2241. https://doi.org/10.1210/jc.2002-021788

[47] Furcron, A.E., Romero, R., Plazyo, O., Unkel, R., Chaemsaithong, P., Mahajan, A., et al. (2015) Vaginal Progesterone, but Not 17a-Hydroxyprogesterone Caproate, Has Antiinflammatory Effects at the Murine Maternal-Fetal Interface. American Journal of Obstetrics \& Gynecology, 213, 846.e1-846.e19.

https://doi.org/10.1016/j.ajog.2015.08.010 
[48] Shiozaki, A., Yoneda, S., Nakabayashi, M., Takeda, Y., Takeda, S., Sugimura, M., et al. (2014) Multiple Pregnancy, Short Cervix, Part-Time Worker, Steroid Use, Low Educational Level and Male Fetus Are Risk Factors for Preterm Birth in Japan: A Multicenter, Prospective Study. Journal of Obstetrics and Gynaecology Research, 40, 53-61. https://doi.org/10.1111/jog.12120

[49] Hassan, S.S., Romero, R., Berry, S.M., Dang, K., Blackwell, S.C., Treadwell, M.C., et al. (2000) Patients with an Ultrasonographic Cervical Length $<$ or $=15 \mathrm{~mm}$ Have Nearly a 50\% Risk of Early Spontaneous Preterm Delivery. Am J Obstet Gynecol, 182, 1458-1467. https://doi.org/10.1067/mob.2000.106851

[50] Heath, V.C., Daskalakis, G., Zagaliki, A., Carvalho, M. and Nicolaides, K.H. (2000) Cervicovaginal Fibronectin and Cervical Length at 23 Weeks of Gestation: Relative Risk of Early Preterm Delivery. BJOG, 107, 1276-1281.

https://doi.org/10.1111/j.1471-0528.2000.tb11620.x

[51] Skupski, D.W., Lin, S.N., Reiss, J. and Eglinton, G.S. (2014) Extremely Short Cervix in the Second Trimester: Bed Rest or Modified Shirodkar Cerclage? Journal of Perinatal Medicine, 42, 55-59. https://doi.org/10.1515/jpm-2013-0092

[52] Szychowski, J.M., Berghella, V., Owen, J., Hankins, G., Iams, J.D., Sheffield, J.S., et al. (2012) Cerclage for the Prevention of Preterm Birth in High Risk Women Receiving Intramuscular 17-a-Hydroxyprogesterone Caproate. The Journal of Maternal-Fetal \& Neonatal Medicine, 25, 2686-2689. https://doi.org/10.3109/14767058.2012.717128

[53] Berghella, V., Rafael, T.J., Szychowski, J.M., Rust, O.A. and Owen, J. (2011) Cerclage for Short Cervix on Ultrasonography in Women with Singleton Gestations and Previous Preterm Birth: A Meta-Analysis. Obstetrics \& Gynecology, 117, 663-671. https://doi.org/10.1097/AOG.0b013e31820ca847

[54] Luusk, M.J., Garden, F.L., Rawlinson, W.D., Naing, Z.W., Cumming, R.G. and Konecny, P. (2016) Cervicitis Aetiology and Case Definition: A Study in Australian Women Attending Sexually Transmitted Infection Clinics. Sexually Transmitted Infections, 92, 175-181. https://doi.org/10.1136/sextrans-2015-052332

[55] Capoccia, R., Greub, G. and Baud, D. (2013) Ureaplasma urealyticum, Mycoplasma hominis and Adverse Pregnancy Outcomes. Current Opinion in Infectious Diseases, 26, 231-240. https://doi.org/10.1097/QCO.0b013e328360db58

[56] Breugelmans, M., Vancutsem, E., Naessens, A., Laubach, M. and Foulon, W. (2010) Association of Abnormal Vaginal Flora and Ureaplasma Species as Risk Factors for Preterm Birth: A Cohort Study. Acta Obstetricia et Gynecologica Scandinavica, 89, 256-260. https://doi.org/10.3109/00016340903418769 